\title{
Anti-Tumor Activity of Oleanolic, Ursolic and Glycyrrhetinic Acid
}

\author{
Ju-Hong Feng ${ }^{1}$, Wei Chen ${ }^{1}$, Yu Zhao ${ }^{2}$ and Xiu-Lian Ju*,1,3 \\ ${ }^{1}$ Hubei Key Laboratory of Novel Reactor \& Green Chemical Technology, School of Chemical Engineering and \\ Pharmacy, Wuhan Institute of Technology, Wuhan 430073, China \\ ${ }^{2}$ Department of Traditional Chinese Medicine and Natural Drug Research, College of Pharmaceutical Sciences, \\ Zhejiang University, Hangzhou 310031, China \\ ${ }^{3}$ Key Laboratory for Green Process of Ministry of Education, Wuhan Institute of Technology, Wuhan 430073, China
}

\begin{abstract}
Over last few years, there has been great interest on the anti-tumor properties of the triterpenoids, oleanolic, ursolic and glycyrrhetinic acid in presence of many plants such as Olea europeae L., Actostaphylos uva-ursi and Glycyrrhiza uralensis. The three acids and their derivatives show potential anti-tumor promoting and cytotoxic activities, inhibiting proliferation, inducing apotosis and preventing invasion, which suggested that they could be developed as anti-cancer and cancer chemopreventive agents. The mechanisms of the anti-tumor effects by triterpenoids need further investigation. A brief review is attempted here for their anti-tumor activities and chemical modification research.
\end{abstract}

Keywords: Oleanolic, ursolic, glycyrrhetinic acid, derivatives, anti-tumor.

\section{INTRODUCTION}

Oleanane and ursane triterpenoids are pentacyclic compounds with 30 carbon atoms, biosynthetically derived from the cyclization of squalene [1]. These natural products, whose structural diversity includes a wide array of functional groups, abound in rosemary, thyme, oregano and lavender, e.g. Olea europeae L., Swertia mileensis T., Ligustrum lucidum Ait. and Actostaphylos uva-ursi [2].

Oleanolic acid (3ß-hydroxy-olean-12-en-28-oic acid, OA) (Fig. 1), an oleanane triterpenoid and ursolic acid ( $3 \beta-$ hydroxy-urs-12-en-28-oic acid, UA) a ursane triterpenoid, are ubiquitous triterpenoids in plant kingdom, medicinal herbs, and are integral part of the human diet [3]. OA and UA have the similar chemical structures but differ only in the position of the methyl group in ring $\mathrm{E}$. OA has two methyl groups at its $\mathrm{C}-20$ position while UA has a respective methyl group at C-19 and C-20 positions.

$18 \beta$-Glycyrrhetinic acid (3ß-hydroxy-11-oxoolean-12-en28-oic acid, GA) (Fig. 1), another oleanane-type triterpenoid, is very structurally similar with oleanolic acid except that it has carbonyl group at C-11 and its carboxyl moiety at C-20 positions. It and its regioisomer $-18 \alpha$-glycyrrhetinic acid both exist in Glycyrrhiza uralensis in the form of free acid or saponin. The saponin, called glycyrrhizic or glycyrrhizin (GL) is composed of glycyrrhetinic acid and two moleculars of glucuronate.

These natural triterpenoids mentioned above are structurally closely and share many common pharmacological properties. Over the last decade, hundreds of articles have been

*Address correspondence to this author at the Hubei Key Laboratory of Novel Reactor \& Green Chemical Technology, School of Chemical Engineering and Pharmacy, Wuhan Institute of Technology, Wuhan 430073, China; Tel: +86-27-87194980; Fax: +86-27-87194465;

E-mail: juxiulian2001@yahoo.com published, reflecting the huge interest and the progress made in the understanding of these substances, including the isolation and purification of triterpenoids from various plants, chemical modifications, pharmacological studies on their beneficial effects, toxicological studies, and the clinical use for the treatment of different diseases, e.g., anticancer chemotherapy [4].

\section{ANTI-TUMOR PROMOTING ACTIVITY}

OA, 18ß-GA, UA and their 3-keto derivatives were studied by Ohigashi's group for their effects on 12-Otetradecanoyl-phorbol-13-acetate (TPA)-induced EpsteinBarr virus (EBV) activation in Raji cells [5]. Both OA and UA significantly inhibited the activation and the dose responses of the acids were very similar to those of the known anti-tumor promoter, retinoic acid. Furthermore, enhancement of the inhibitory activity was found in 3-keto derivatives of OA and UA while oxidation at C-3 of GA led to reduction of the activity. Huang's team also reported that the 3-keto derivatives of OA might be a useful anticancer agent for melanoma [6].

In 1986, OA and UA were tested against inhibitory effect on tumor promotion by TPA in vivo [7]. They inhibited effectively the tumor promotion in mouse skin and the role of UA for inhibitory action on tumor promotion might differ slightly from those of $\mathrm{OA}$ and retinoic acid. Using the same bioassay technique, the following reports suggested that some oleanone and ursane diols and triols could be useful as chemopreventive agents $[8,9]$.

It's reported that $18 \beta-$ GA was more effective than $18 \alpha-$ GA to inhibit the mutagenicity of benzo[a]pyrene, 2aminofluorene and aflatoxin $\mathrm{B}_{1}$ in Salmonella typhimurium TA98 and TA100 [10]. The acids exhibited substantial antiskin tumor initiating and anti-skin tumor promoting activities. 


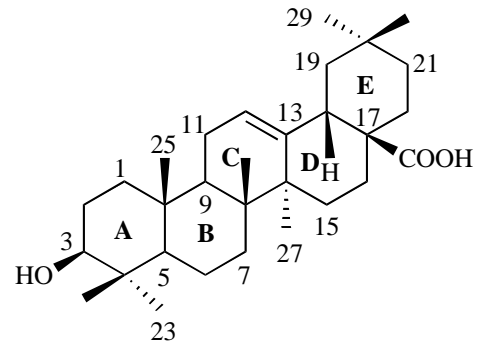

oleanolic acid

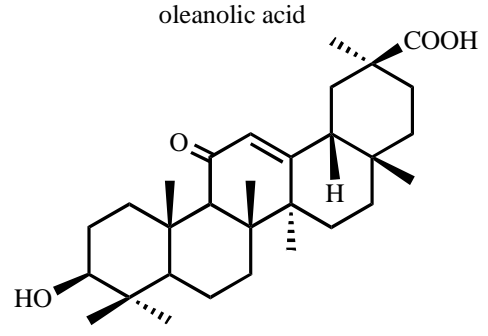

18ß-glycyrrhetinic acid
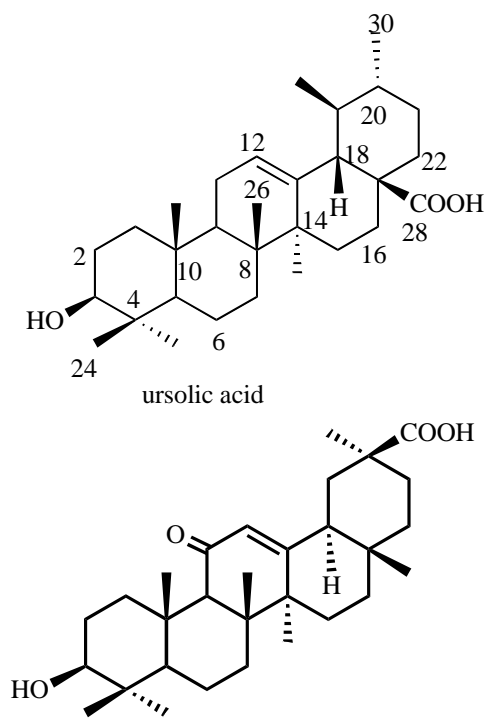

$18 \alpha$-glycyrrhetinic acid

Fig. (1). Structures of the triterpenoids.

\section{CYTOTOXIC ACTIVITY}

The cytotoxic activities of these triterpenoids and their derivatives were investigated widely.

UA and its related derivatives were tested for their cytotoxic activity on lymphocytic leukemia cells P-388, L-1210, human oral epidermoid carcinoma KB, human lung carcinoma cell A-549, human ileocecal carcinoma HCT-8 and human mammary gland carcinoma MCF-7 tumor cell lines [11]. Esterification of the hydroxyl group at C-3 and the carboxyl group at $\mathrm{C}-17$ positions led to compounds with decreased cytotoxicity in the human tumor cell lines, but with equivalent or slightly increased activity against the growth of L-1210 and P-388 leukenic cells.

The cytotoxicity activities of OA and UA on Jurkat cell line ( $\mathrm{T}$ cell lymphoma) were reported [12]. The results suggested that UA and OA have significant anti-tumor activity and UA is more effective than OA with $\mathrm{IC}_{50}$ values of $75 \mu \mathrm{M}$ and $150 \mu \mathrm{M}$, respectively. The anti-tumor mechanism of the acids was supposed to be killing the cells by cytotoxin with high dose $(100 \mu \mathrm{M})$ and inhibiting the proliferation of cells with low dose $(50 \mu \mathrm{M})$.

UA, 3-keto derivatives of OA and UA isolated from the aerial roots of Ficus microcarpa were tested their cytotoxic activities in vivo using three human cancer cell lines, namely, HONE-1 nasopharyngeal carcinoma, KB oral epidermoid carcinoma, and HT29 colorectal carcinoma cells [13]. These three natural products showed remarkable cytotoxicity against the cell lines.

The effects of UA on the proliferation of mouse melanoma cell line B16 were studied by Es-saady group and it inhibited $\mathrm{B} 16$ proliferation with an $\mathrm{IC}_{50}$ value of $10 \mu \mathrm{M}$ by MTT technique [14]. The derivatives of OA and UA could also inhibit the proliferation of cell lines such as WI-38 lung fibroblast cells, VA-13 malignant tumor cells and HepG2 human liver tumor cells [15].

$\mathrm{OA}$ and UA were examined for their ability to inhibit the tumor growth and enhance the recovery of hematopoietic system postirradiation in mice [16]. UA was more potent tumorigenic inhibitor than OA.

$\mathrm{OA}$ and UA as the anticancer constituents were isolated from Pterocarya tonkinesis by a bioassay using tsFT210 cells [17]. The acids inhibited the proliferation of human erythroleukemia K562 cells with the inhibition rates of $42.4 \%$ and $33.7 \%$ at $10 \mathrm{mg} \cdot \mathrm{L}^{-1}$, respectively.

The anti-tumor activities of OA, 18ß-GA and UA were studied by Huang's group in detail. The research on the proliferation inhibition and differentiation induction of 18ß-GA and GL on human hepatocarcinoma cells BEL-7402 has been reported [18]. In the same effect, the dosage of 18ß-GA is lower about 40 times than that of GL. Subsequently the inhibitory effect of GL, 18 $\beta$-GA, OA and UA on the proliferation and invasion of the human lung cancer cells PGCL3 were investigated [19]. The mechanism of anti-invasion might be to inhibit the adhesion, migration and the $\mathrm{CB}$ secretion of the cells. Both OA and UA could decrease the proliferation of PGCL3 cells, and their IC $_{50}$ values were $40.71 \mu \mathrm{M}$ and $44.73 \mu \mathrm{M}$ respectively. The combination of retinoic acid and $18 \beta-G A$ had synergistic effect against the proliferation of PGCL3 cells [20].

The mechanism of UA induced effects on K562 cells was reported [21]. The results showed that UA inhibited K562 cells proliferation in a dose-dependent manner. Apparent morphological index of apoptosis was observed. Expression of Bcl-2 was down-regulated, but Bax expression was enhanced. Activation of Caspase-3 and down-regulation of phosphotyrosine was determined. These results indicated that UA could induce apoptosis in K562 cells in vitro. Upregulation of Bax and activation of Caspase-3 might contribute to this effect.

\section{CHEMICAL MODIFICATION}

Efforts have been made to produce more effective and less toxicity derivatives of these triterpenoids by chemical modification (Fig. 2). 
<smiles>[R][R](=O)OOC([R])=O</smiles><smiles>[R][R](=O)ON</smiles>

ref. [25]

$\mathrm{R}^{1}=\alpha-\mathrm{H} \beta-\mathrm{OH}, \alpha-\mathrm{H} \beta-\mathrm{OAc}$, $\alpha-\mathrm{H} \beta-\mathrm{NH}_{2}, \mathrm{O}, \mathrm{N}-\mathrm{OH}$

$\mathrm{R}^{2}=\mathrm{O}, \mathrm{H}_{2}$ $\mathrm{R}^{3}=\mathrm{COOCH}_{3}, \mathrm{COOH}$, $\mathrm{CONH}_{2}\left(\mathrm{CH}_{2}\right)_{9} \mathrm{NH}_{2}$

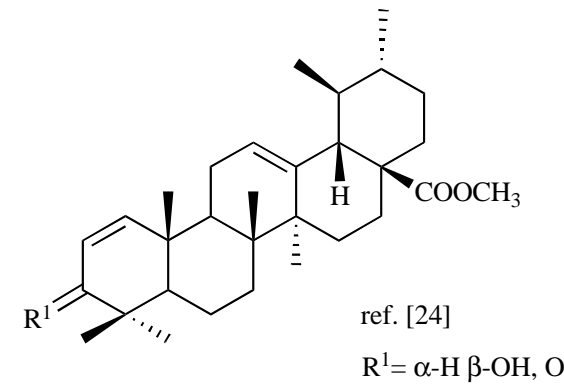

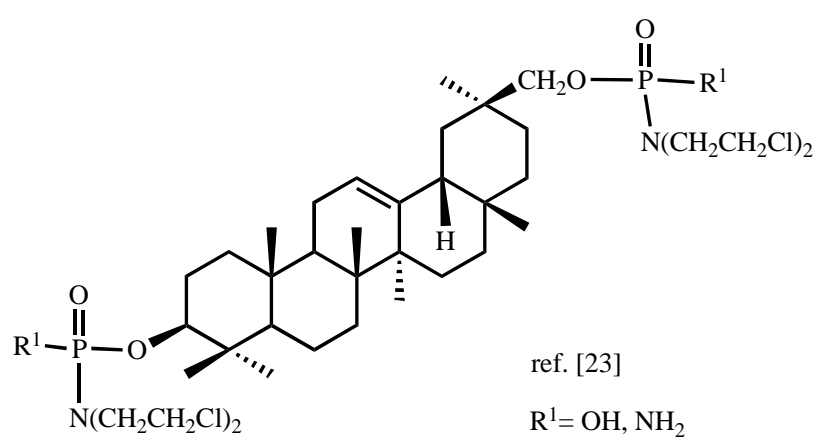

$\mathrm{R}^{1}$<smiles>C=C1C=C2[C@H]3C[C@H](I)[C@@H]3CC[C@]2(C)[C@@]2(C)CCC3C(C)(C)C(=[IH])CC[C@]3(C)C12</smiles>

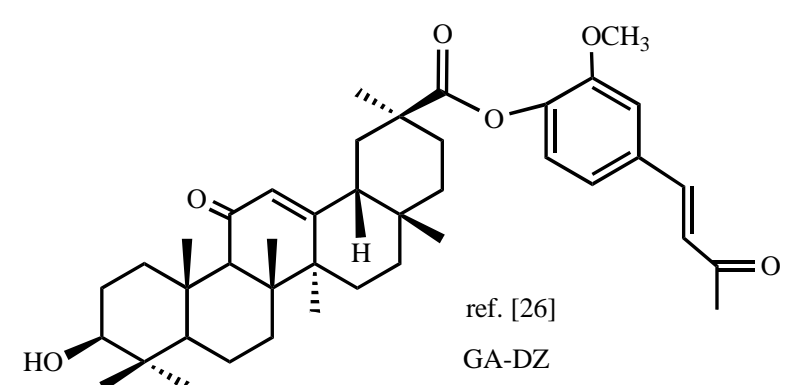

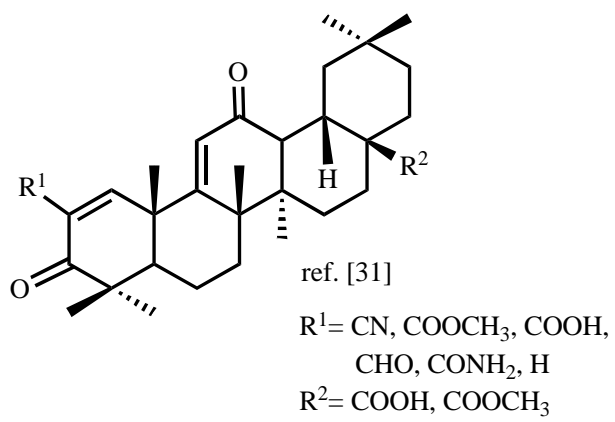

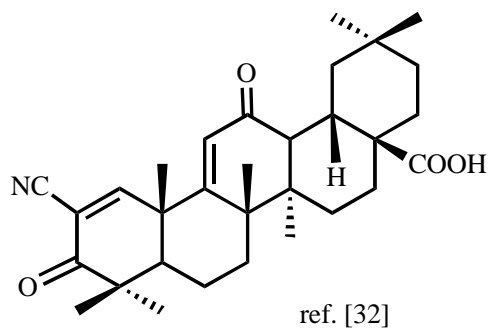

CDDO

Fig. (2). Strucures of OA, UA and GA derivatives by chemical modification.

Terasawa's group reported a series of modified derivatives of $18 \alpha$ - and $18 \beta-\mathrm{GA}$ and their anti-tumor-promoter activities of TPA in vitro [22]. The structure-activity relationships (SAR) study showed that the predominant factors for the high anti-tumor-promoter activity in GA series compounds to be the hydrophobic character of the ring A moiety, the presence of an 11-oxo function, and the introduction of a 20-hydroxymethyl group. No essential difference was found for inhibitory effects between the $18 \alpha$ - and $18 \beta$-series.

Six new GA derivatives were synthesized from the reaction of di(2-chloroethyl)-aminophosphonyl dichloride with methyl glycyrrhetinate, methyl-11-deoxy-glycyrrhetinate, and olean-12-en-3 $\beta, 30$-diol, respectively [23]. The preliminary anti-tumor activity against EAC cells both in vitro and in vivo showed that the new compounds exhibited potent anti-tumor activities in comparison with the nitrogen mustard.

Oxidation of UA on its 1, 2 and 3-positions was carried out and the models of Hela human cervical carcinoma cells and HL-60 cells were used for bioactive screening [24]. The results indicated that introduction of the oxidized substituent groups in ring $\mathrm{A}$ of UA led to the decrease of anti-tumor activities.

Structural modifications were performed on the C-3, C28 and C-11 positions of UA and the cytotoxicity of the derivatives was evaluated [25]. The SAR study revealed that the triterpenoids possessing two hydrogen-bond forming groups (an $\mathrm{H}-$ donor and a carbonyl group) at C-3 and C-28 positions exhibit cytotoxic activity. A $3 \beta$-amino derivative was 20 times more potent than the parent UA. 

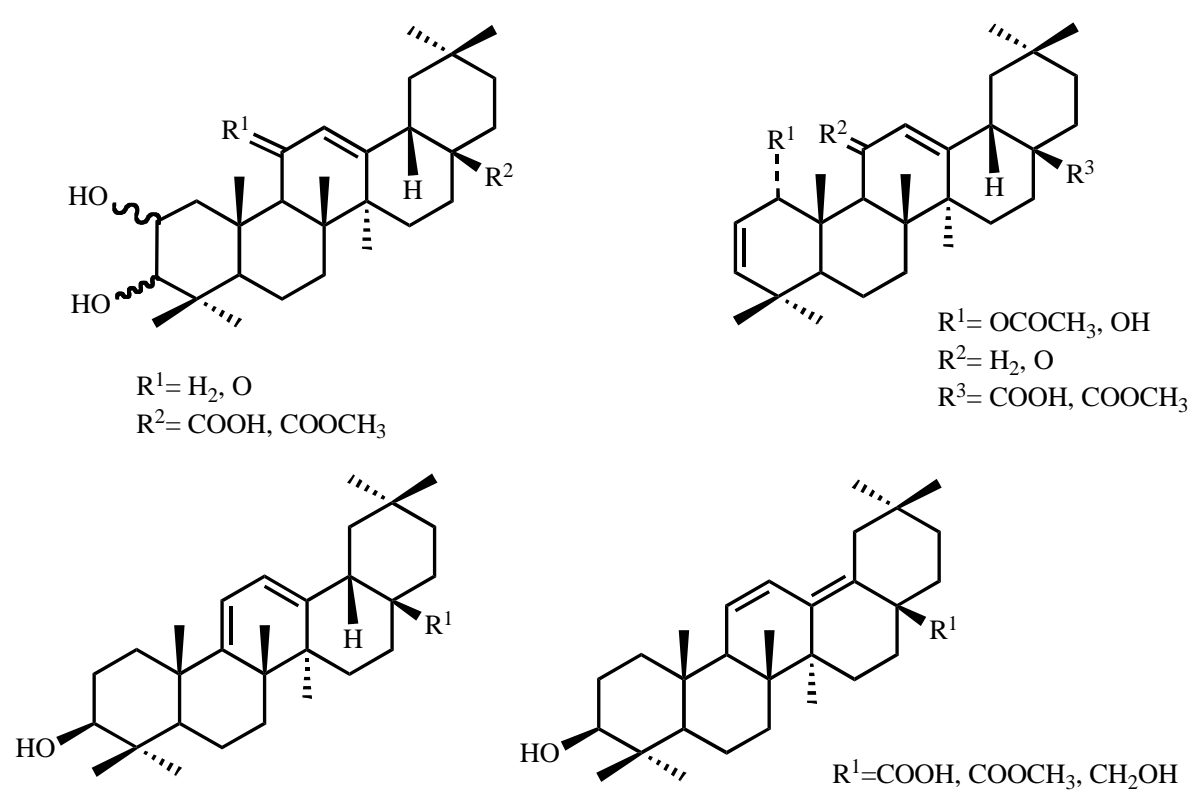

Fig. (3). Structures of OA derivatives synthesized by the authors.

In an in vitro anti-cancer assay, using nine different human tumor cell lines, the GA-DZ (dehydrozingerone) conjugates showed significant cytotoxic effects [26]. Similar conjugates between DZ and OA or UA were inactive suggesting that the GA component is critical for activity.

Since 1997, Honda's group had commenced the research on the inhibitory effect of UA and OA on nitric oxide (NO) production induced by interferon- $\gamma$ (IFN- $\gamma$ ) in mouse macrophage [27-31]. Excessive production of NO can destroy functional normal tissues during acute and chronic inflammation. This phenomenon is also closely related mechanistically to carcinogenesis. Thus, inhibitors of NO production in macrophage are potential anti-inflammatory and cancer chemopreventive drugs. About sixty OA and UA derivatives were initially randomly synthesized to test their inhibitory of NO production in mouse macrophage. The results provided the following interesting SAR: 1) in the A ring, a 1-en-3-one functionality was important for significant activity; 2) the oleanane skeleton was more potent than the ursane skeleton; 3) carboxyl, methoxycarbonyl and nitrile groups at C-2 enhanced activity, however, hydroxyl, aminocarbonyl, methoxy, chloride, and bromide groups decreased activity while a formyl group did not confer activity but only toxicity; 4) a 9(11)-en-12-one functionality was the strongest enhancer of potency among structures of ring $\mathrm{C}$. The selected oleanane triterpenoid, 2-cyano-3,12-dioxooleana-1,9(11)dien-28-oic acid (CDDO) was found to be a potent, multifunctional agents in various in vitro assays [32].

\section{CONCLUSION}

The triterpenoids, OA, UA and GA have attracted considerable interest because of their low cytotoxicity and their range of biological activities [4]. Over the last few years, there has been great interest on the part of researchers in the chemopreventive, cytotoxic properties of the three triterpenoids. According to Ovesna et al. [2], these triterpenoids and their derivatives can act on various stages of tumor development, including the inhibition of tumorigenesis, inhibition during tumor promotion, and induction of tumor cell differ- entiation. Finally, OA, UA and GA are capable of interference with many processes going on in normal and malignant cells. However, many aspects of their biological activities are not understood properly. The mechanisms of the antitumor effects by triterpenoids need further investigation.

Our research group has been interested in the SAR study of OA, UA and GA. We had designed and synthesized more than one hundred derivatives of these triterpenoids, which have dihydroxyl groups with different configurations, enone moieties, allylic alcohol functionalities, along with conjugated homoannular and heteroannular diene frames (the structures of OA derivatives illustrated in Fig. 3). The preliminary biological assays showed that some derivatives had more potent cytotoxic activity than cisplatin against $\mathrm{KB}$, BEL7404, A549, HL-60, CNE and PC-3 cell lines [33]. The further SAR research has been in process.

\section{REFERENCES}

[1] Connolly, J.D.; Overton, K.H. Chemistry of Terpenes and Terpenoids. Newman Academic Press: New York, 1972.

[2] Ovesná, Z.; Vachálková, A.; Horváthová, K.; Tóthová, D. Neoplasma, 2004, 51, 327-333.

[3] Somova, L.O.; Nadar, A.; Rammanan, P.; Shode, F.O. Phytomedicine, 2003, 10, 115-121.

[4] Liu, J. J. Ethnopharmacol., 2005, 100, 92-94.

[5] Ohigashi, H.; Takamura, H.; Koshimizu, K.; Tokuda, H.; Ito, Y. Cancer Lett., 1986, 30, 143-151.

[6] Tokuda, H.; Ohigashi, H.; Koshimizu, K.; Ito, Y. Cancer Lett., 1986, 33, 279-285.

[7] Huang, D.; Ding, Y.; Lia, Y.; Zhang, W.M.; Fang, W.S.; Chen, X.G. Cancer Lett., 2006, 233, 289-296.

[8] Nishino, H.; Nishino, A.; Takayasu, J.; Hasegawa, T.; Iwashima, A.; Hirabayashi K.; Iwata, S.; Shibata, S. Cancer Res., 1988, 48, 5210-5215.

[9] Ukiya, M.; Akihisa, T.; Tokuda, H.; Suzuki, H.; Mukainaka, T.; Ichiishi, E.; Yasukawa, K.; Kasahara, Y.; Nishino, H. Cancer Lett., 2002, 177, 7-12.

[10] Wang, Z.Y.; Agarwal, R.; Zhou, Z.C.; Bickers, D.R.; Mukhtar, H. Carcinogenesis, 1991, 12, 187-192.

[11] Lee, K.H.; Lin, Y.M.; Wu, T.S.; Zhang, D.C.; Yamagishi, T.; Hayashi, T.; Hall, H.I.; Chang, J.J.; Wu, R.Y.; Yang, T.H. Planta Med., 1988, 54, 308-311. 
[12] Li, J.; Xu, L.Z.; Zhu, W.P.; Zhang, T.M.; Li, X.M.; Jin, A.P.; Huang, K.M.; Li, D.L.; Yang, Q.R. Chin. Oncol., 1999, 9, 395-397.

[13] Chiang, Y.M.; Chang, J.Y.; Kuo, C.C.; Chang, C.Y.; Kuo, Y.H. Phytochemistry, 2005, 66, 495-501.

[14] Es-saady, D.; Simon, A.; Ollier, M.; Maurizis, J.C.; Chulia, A.J.; Delage, C. Cancer Lett., 1996, 106, 193-197.

[15] Fu, L.W.; Zhang, S.J.; Li, N.; Wang, J.L.; Zhao, M.; Sakai, J.; Hasegawa, T.; Mitsui, T.; Kataoka, T.; Oka, S.; Kiuchi, M.; Hirose, K.; Ando, M. J. Nat. Prod., 2005, 68, 198-206.

[16] Hsu, H.Y.; Yang, J.J.; Lin, C.C. Cancer Lett., 1997, 111, 7-13.

[17] Liu, H.B.; Cui, C.B.; Cai, B.; Gu, Q.Q.; Zhang, D.Y.; Wen, J.N.; Guan, H.S. Chin. J. Med. Chem., 2004, 14, 165-168.

[18] Huang, W.; Huang, J.Q.; Zhang, D.F.; Liao, Z.Q. Chin. J. Trad. Med. Sci. Tech., 2002, 9, 92-94.

[19] Huang, W.; Huang, J.Q.; Zhang, D.F.; Zhang, R.L.; Liao, Z.Q. Chin. J. Lung. Cancer, 2003, 6, 254-257.

[20] Huang, W.; Huang, J.Q.; Zhang, D.F.; Liao, Z.Q. Bull. Chin. Cancer, 2003, 12, 665-667.

[21] Zhang, Q.P.; Xie, L.K.; Deng, T.; Hu, Z.F.; Chen, H.M.; Tan, J.Q. Basic Med. Sci. Clin., 2004, 24, 414-417.

[22] Terasawa, T.; Okada, T.; Nishino, H. Eur. J. Med. Chem., 1992, 27, 689-692.

[23] Jin, J.M.; Liu, X.F.; Xu, H.S. Chin. J. Appl. Chem., 2001, 18, 869872.

[24] Bai, Y.J.; Yang, X.S.; Kang, W.Y.; Hao, X.J.; Xu, X.J.; Song, B.A. West China J. Pharm. Sci., 2003, 38, 87-90.
[25] Ma, C.M.; Cai, S.Q.; Cui, J.R.; Wang, R.Q.; Tu, P.F.; Hattori, M.; Daneshtalab, M. Eur. J. Med. Chem., 2005, 40, 582-589.

[26] Tatsuzaki, J.; Taniguchi, M.; Bastow, K.F.; Nakagawa, G.K.; Morris, N.S.L.; Itokawa, H.; Baba, K.; Lee, K.H. Bioorg. Med. Chem., 2007, 15, 6193-6199.

[27] Honda, T.; Finlay, H.J.; Gribble, G.W.; Suh, N.; Sporn, M.B. Bioorg. Med. Chem. Lett., 1997, 7, 1623-1627.

[28] Honda, T.; Rounds, B.V.; Gribble, G.W.; Suh, N.; Wang, Y.P.; Sporn, M.B. Bioorg. Med. Chem. Lett., 1998, 8, 2711-2714.

[29] Honda, T.; Rounds, B.V.; Bore, L.; Favaloro, J.F.G.; Gribble, G.W.; Suh, N.; Wang, Y.P.; Sporn, M.B. Bioorg. Med. Chem. Lett., 1999, 9, 3429-3434.

[30] Honda, T.; Gribble, G.W.; Suh, N.; Finlay, H.J.; Rounds, B.V.; Bore, L.; Favaloro, J.F.G.; Wang, Y.P.; Sporn, M.B. J. Med. Chem., 2000, 43, 1866-1867.

[31] Honda, T.; Rounds, B.V.; Bore, L.; Finlay, H.J.; Favaloro, J.F.G.; Suh, N.; Wang, Y.P.; Sporn, M.B.; Gribble, G.W. J. Med. Chem., 2000, 43, 4233-4246.

[32] Suh, N.; Wang, Y.P.; Honda, T.; Gribble, G.W.; Dmitrovsky, E.; Hickey, W.F.; Maue, R.A.; Place, A.E.; Porter, D.M.; Spinella, M.J.; Williams, C.R.; Wu, G.F.; Danneberg, A.J.; Flanders, K.C.; Letterio, J.J.; Mangelsdorf, D.J.; Nathan, C.F.; Nguyen, L.; Porter, W.W.; Ren, R.F.; Roberts, A.B.; Roche, N.S.; Subbaramaiah, K.; Sporn, M.B. Cancer Res., 1999, 59, 336-341.

[33] Zhao, Y.; Feng, J.H.; Zhou, C.X.; Bai, H.; Wu, X.M. C.N. 1796401, Patent, 2006

Received: October 20, 2008

Revised: November 08, 2008

Accepted: February 24, 2009

(C) Feng et al.; Licensee Bentham Open.

This is an open access article licensed under the terms of the Creative Commons Attribution Non-Commercial License (http://creativecommons.org/licenses/by-nc/3.0/) which permits unrestricted, non-commercial use, distribution and reproduction in any medium, provided the work is properly cited. 